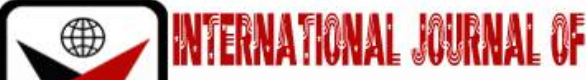 \\ בmas
}

ISSN 2278 - 0211 (Online)

\section{Effect of Timing of Cord Clamping on Oxygen Saturation}

\begin{tabular}{c}
\hline Dr. Jibril, Amina Oziwere \\
Lecturer, Department of Pediatrics, \\
University of Abuja Teaching Hospital Gwagwalada, FCT, Nigeria \\
Dr. Ajanaku, Iember Talatu \\
Lecturer, Department of Pediatrics, \\
University of Abuja Teaching Hospital, Gwagwalada, FCT, Nigeria \\
\hline
\end{tabular}

\begin{abstract}
:
Background: The timing of cord clamping affects the total blood volume of the neonate, and this directly impacts circulatory stability and the likelihood of survival of the neonate. Critical oxygen delivery as evidenced by oxygen saturation can be affected by cord clamping practices.

Objective: To determine the effect of timing of cord clamping on oxygen saturation within the first hour of birth. Materials and Methods: This was analytical cohort study carried out on 262 term newborns born at the University of Abuja Teaching Hospital from 5th May to 10th November 2015. 132 had immediate cord clamping and 130 were delayed. Oxygen saturation using pulse oximetry was measured every 15 minutes within first hour of life

Results: there was a gradual improvement in oxygen saturation with increasing time within the first hour with statistical significance in favor of delayed cord clamping with $p<0.05$. at each 15-minute interval.

Discussion: Delayed cord clamping had a positive effect on oxygen saturation when compared to immediate cord clamping. The values were higher and this implied quicker circulatory stability for them. However, beyond one minute of delay, the oxygen saturation values were not statistically significant.

Conclusion: Delayed cord clamping conferred better oxygen saturation values within the first hour of life.
\end{abstract}

Keywords: Oxygen, saturation, circulation, stability

\section{Introduction}

Oxygen saturation refers to the percentage of haemoglobin molecules in the arterial blood which are saturated with oxygen.(Pole, 2002) The term $\mathrm{SpO}_{2}$ (saturation of peripheral oxygen) is the equivalent of $\mathrm{SaO}_{2}($ arterial oxygen saturation) measurement determined by pulse oximetry (Philips, 2003). During neonatal resuscitation, the use of pulse oximetry gives rapid accurate measures of heart rate and $\mathrm{SpO}_{2} \cdot\left(\mathrm{O}^{\prime}\right.$ Donnell, Kamlin, Davis, \& Morley, 2005) current neonatal resuscitation protocols advice delayed umbilical cord clamping.(Kattwinkel et al., 2010)

The umbilical cord is a critical conduit for blood flow between mother and baby,(Ganong, 2005) thus the timing of cord clamping at birth affects the newborn's circulatory stability(Cavaliere, 2004) and the likelihood of survival of the neonate.(Mercer, Vohr, Erickson-Owens, Padbury, \& Oh, 2010) Clamping the cord before spontaneous breathing was achieved was found to be associated with increased risk of death or neonatal admissions.(Hege, Ersdal, \& Linde, 2014) This study explored the effect of timing of cord clamping on oxygen saturation.

\section{Objectives}

The aim of this study was to determine how varying cord clamping timing (immediate versus delayed) affected the oxygen saturation of term neonates within the first hour of life.

\section{Methods}

It was an analytical cohort study carried out in the delivery suites of the Department of Obstetrics and Gynecology, the post-natal ward and the Special Care Baby Unit of the University of Abuja Teaching Hospital within a six month period (May 2015 to November 2015). A total of 300 term newborn were recruited into the study after satisfying the inclusion criteria (uncomplicated vaginal delivery at $\geq 37$ completed weeks gestational age). Exclusion criteria included delivery beyond 42 completed weeks' gestation, congenitally malformed babies, need for immediate resuscitation and presence of risk factors for anemia, polycythemia and hyperbilirubinemia e.g. antepartum hemorrhage, infants of diabetic mothers, ABO or Rh incompatibility. Of the total babies studied, only 262 had their oxygen saturation measured fully in 15 minute intervals from birth till the end of the first hour of life and were analyzed. Ethical approval was given by the hospital ethics committee.

All mothers who signed consent to participate were systematically randomized into either of two group by way of picking a closed slip of paper from an unmarked jar. Each slip had been labelled with either the letter A (for immediate 
clamping) or B (for delayed clamping).The mother reserved the right to know which group she fell into. The timing for ICC group was within 30 seconds of delivery while the timing for the DCC group was within 60-90 seconds post-delivery.

SPO2 was recorded with a hand held neonatal pulse oximeter (Devon ${ }^{\circledR}$ PC-66 combo pulse oximeter, Devon Medical Inc, Pennsylvania, USA). The pulse oximeter probe was applied to the right hand (thumb or middle finger) and the point of application was kept warm to avoid spurious readings due to hypothermia. The readings were taken in 15 minute intervals up to the end of the first jour of life.

Other essential parameters were recorded, including but not limited to Apgar score, birth weight, length, head circumference and mother's biodata. Social status was determined using Olusanya classification. The questionnaire was administered by the investigator once consent to participate in the study was obtained from the respondents.

Statistical analysis was done using the Statistical Package for Social Sciences (SPSS) version 20. The means and standard deviation (SD) were computed for the quantitative variables (oxygen saturation). The difference between the two means (values for immediate cord clamping versus delayed cord clamping) were compared using the Student t test, while difference between proportions (e.g. gender, occupation, social status) were compared using chi-square test. Analysis of variance (ANOVA) was used to compare the means among greater than two groups, with the aim to determine any significant effect on oxygen saturation with increasing duration of placental transfusion. $\mathrm{P}$ value $<0.05$ was considered as significant. Confidence interval of $95 \%$ was assumed.

\section{Results}

The effect of timing of cord clamping on oxygen saturation is as shown in the table below. It shows a gradual improvement in the oxygen saturation with increasing delay of cord clamping. The study was able to depict statistical significance in favour of DCC with a range of $p$ values all $<0.05$ for the various timing intervals used.

\begin{tabular}{|c|c|c|c|c|}
\hline $\begin{array}{c}\text { Oxygen saturation } \\
\mathbf{N}=\mathbf{2 6 2}\end{array}$ & $\begin{array}{c}\text { Cord Clamping } \\
\text { Methods } \\
\text { ICC } \\
\text { Mean(SD) } \\
\mathbf{n = 1 3 2}\end{array}$ & $\begin{array}{c}\text { DCC } \\
\text { Mean(SD) n-130 }\end{array}$ & p-value & $\begin{array}{c}\text { Confidence } \\
\text { interval }\end{array}$ \\
\hline $\mathrm{SpO}_{2}$ at 0 minute & $84.5(5.6)$ & $86.2(5.2)$ & $0.014^{*}$ & $-3.068--0.338$ \\
\hline $\mathrm{SpO}_{2}$ at 15 minutes & $88.7(3.7)$ & $89.9(3.8)$ & $0.016^{*}$ & $-2.052--0.163$ \\
\hline $\mathrm{SpO}_{2}$ at 30 minutes & $91.3(2.6)$ & $92.7(2.6)$ & $<0.001^{*}$ & $-2.052--0.752$ \\
\hline $\mathrm{SpO}_{2}$ at 45 minutes & $93.6(2.1)$ & $94.5(2.1)$ & $0.001^{*}$ & $-1.463--0.391$ \\
\hline $\mathrm{SpO}_{2}$ at 60 minutes & $95.3(1.5)$ & $96.2(1.5)$ & $<0.001^{*}$ & $-1.231--0.465$ \\
\hline
\end{tabular}

Table 1: Effect of Cord Clamping Timing on Oxygen Saturation

Key: N- Total Number Of Subjects, $N$ - Number of Subjects in Each Group, Spo $2^{-}$Oxygen Saturation, SD-Standard Deviation, * $P<0.05, C I-$ Confidence Interval.

Application of analysis of variance did not yield any significant difference in oxygen saturation across the three subgroups of delayed cord clamping, with all $\mathrm{p}$ values $>0.05$ as depicted in table below. This gave the impression that beyond one minute, no added advantage with respect to circulatory stability.

\begin{tabular}{|c|c|c|c|c|c|}
\hline Red cell indices & $\begin{array}{c}\mathbf{6 0 - 6 9} \\
\text { Mean(SD) } \\
\mathbf{n = 7 5}\end{array}$ & $\begin{array}{c}\text { Timing(seconds) } \\
\text { Mean(SD) } \mathbf{n = 2 7}\end{array}$ & $\begin{array}{c}\mathbf{8 0 - 9 0} \\
\text { Mean(SD) } \mathbf{n = 2 8}\end{array}$ & F & p-value \\
\hline $\mathrm{SpO}_{2}$ at $0 \mathrm{~min}$ & $86.2(5.1)$ & $86.4(4.8)$ & $86.1(6.1)$ & 0.029 & 0.971 \\
\hline $\mathrm{SpO}_{2}$ at $15 \mathrm{~min}$ & $89.7(3.7)$ & $89.9(3.5)$ & $90.5(4.5)$ & 0.443 & 0.643 \\
\hline $\mathrm{SpO}_{2}$ at $30 \mathrm{~min}$ & $92.7(2.4)$ & $92.4(2.6)$ & $93.2(2.9)$ & 0.536 & 0.587 \\
\hline $\mathrm{SpO}_{2}$ at $45 \mathrm{~min}$ & $94.5(2.2)$ & $94.1(2.1)$ & $95.2(2.1)$ & 1.885 & 0.156 \\
\hline $\mathrm{SpO}_{2}$ at $60 \mathrm{~min}$ & $96.1(1.5)$ & $96.2(1.7)$ & $96.4(1.4)$ & 0.299 & 0.742 \\
\hline
\end{tabular}

Table 2: Relationship of Increased Timing on Oxygen Saturation

Key: $\mathrm{SPO}_{2}$ - Oxygen Saturation, SD-Standard Deviation

\section{Discussion}

The oxygen saturation values were measured in intervals of 15 minutes from birth. We were able to depict significant difference in the oxygen saturation when comparing babies who had immediate cord clamping with those who had delayed cord clamping, in favour of the delayed cord clamping group. Babies who had delayed cord clamping had higher $\mathrm{SpO}_{2}$ values within the first hour of life, which is expected because they received more red cells at the point of delivery, which functionally translates into increased oxygen carrying capacity of the blood. This finding could thus infer that faster stability of the circulation was achieved in babies who had delayed cord clamping. This direct measurement of oxygen carrying capacity in relation to cord clamping practices has not been extensively studied previously.

A study by Baenziger et al(Baenziger et al., 2007) in Zurich with similar methodology as this current study (immediate cord clamping at < 20 seconds; delayed cord clamping between $60-90$ seconds) studied the effect of timing of cord clamping on postnatal cerebral oxygenation. Though they used a near-infrared spectroscopy method to measure cerebral oxygenation, their results proved that delayed cord clamping improved cerebral oxygenation.(Baenziger et al., 
2007)The study showed improved oxygenation with delayed cord clamping in the cerebrum measured with a near infrared spectroscopy while this study showed improved oxygenation using pulse oximetry.

\section{Conclusion}

Delaying cord clamping has been shown, amongst its other advantages, to confer better oxygen saturation values within the first hour of life. This cost effective maneuver will ensure better neonatal transition at birth.

\section{References}

i. $\quad$ Pole Y. Evolution of pulse oximetry. Int Congr Ser. 2002; 1242:137-44.

ii. Philips medical systems. Understanding Pulse Oximetry Concepts. 2003.

iii. O’Donnell CP, Kamlin CO, Davis PG, Morley CJ. Obtaining pulse oximetry data in neonates: a randomised crossover study of sensor application techniques. Arch Dis Child Fetal neonatal Ed 2005; 90(1):84-5.

iv. Kattwinkel J, Perlman JM, Aziz K, et al. Part 15: Neonatal resuscitation: 2010 American Heart Association Guidelines for Cardiopulmonary Resuscitation and Emergency Cardiovascular Care. Circulation 2010; 122: 90919.

v. Ganong W. Placental and foetal circulation. In: WF G, editor. Review of medical physiology. 22nd ed. Boston: McGraw Hill; 2005. p. 627-9.

vi. $\quad$ Cavaliere T. Red Blood Cell Indices: Implications for Practice. NAINR. 2004;4(4):231-9.

vii. Mercer JS, Vohr BR, Erickson-Owens DA, Padbury JF, Oh W. Seven-month developmental outcomes of very low birth weight infants enrolled in a randomized controlled trial of delayed versus immediate cord clamping. J Perinatol 2010; 30: 11-6.

viii. Hege A, Ersdal L, Linde J. Neonatal Outcome Following Cord Clamping After Onset of Spontaneous Respiration. Pediatrics. 2014;134(2):265-72.

ix. Baenziger O, Stolkin F, Keel M, von Siebenthal K, Fauchere J-C, Das Kundu S, et al. The influence of the timing of cord clamping on postnatal cerebral oxygenation in preterm neonates: a randomized, controlled trial. Pediatrics [Internet]. 2007;119(3):455-9. Available from: http://www.ncbi.nlm.nih.gov/pubmed/17332197. 